\title{
Individual Option Prices for Climate Change Mitigation
}

\author{
by \\ T.A. Cameron \\ UCLA and University of Oregon
}

\begin{abstract}
Willingness to pay for climate change mitigation depends on people's perceptions about just how bad things will get if nothing is done. Individual subjective distributions for future climate conditions are combined with stated preference discrete choice data over alternative climate policies to estimate individual option prices (the appropriate ex ante welfare measure in the face of uncertainty) for climate change mitigation. We find significant "scope" effects in the estimated option prices - according to both expected conditions and degree of uncertainty.
\end{abstract}

Keywords: option prices, climate change, stated preferences, contingent valuation, statedependent preferences

JEL Classifications: H0, D8, N5, Q2

Address: Department of Economics, 435 PLC

1285 University of Oregon

Eugene, OR 97403-1285

(541)346-1242 fax (541)346-1243

cameron@darkwing.uoregon.edu

Date: July 20, 2002 


\section{Individual Option Prices for Climate Change Mitigation}

\section{Introduction}

The willingness of the voting public to incur substantial costs in order to prevent climate change will be a key determinant of the success or failure of domestic and international climate policy. Consequently, it is important to gain some understanding about how individuals formulate subjective conceptions of future climate prospects in the absence of mitigation, and how these opinions translate into willingness to pay for climate change mitigation in terms of higher prices or taxes.

Global climate change does seem to have the potential to result in detectable shifts in the distributions of many environmental measures. Past scientific controversy over the nature and magnitude of these changes, however, has made it very difficult for legislators to agree on optimal climate change policies. Some constituencies cannot even agree on the necessity for costly measures to mitigate climate change. In democratic jurisdictions, support for legislation to manage the world's climate depends on the distribution in the population of individuals' ex ante willingness to pay to avoid the perceived consequences of failing to act. Citizens are asked to vote on policies (directly or indirectly) in advance of knowing the resolution of uncertainty about what will happen if nothing is done. ${ }^{1}$

What do people perceive to be the consequences of pursuing no special policies to manage the world's climate? Individuals who have lived for some time in a particular location have become accustomed to the typical patterns of seasonal temperatures, rainfall, cloud cover,

\footnotetext{
${ }^{1}$ Some early research on the topic of how people make judgments in the presence of uncertainty is described in Tversky and Kahneman (1974)
} 
and humidity in their local area. Absent any appreciation of the forces that might produce systematic changes in these climate variables, individuals may assume that the current average patterns will persist indefinitely. Other people have begun to recognize that, without policies to prevent these changes, shifts in the distributions of their local climate variables may occur.

Cameron and Englin (1997) make the point that in stated preference assessment of the demand for a public good, subjects who are queried about their willingness pay for the provision of the good will approach the question with two types of information. First, they are likely to have different amounts of "native information" (prior knowledge or past experience with the type of good in question). Second, the researcher will typically provide additional information about the nature of the good in an effort to induce the subject to respond on the ideal basis of “full information" as prescribed by Arrow, et al. (1993). Researchers will sometimes proceed on the assumption that the information provided in the survey itself represents the complete information set upon which individuals are making their policy choices. Here, we delve further into the issue of heterogeneous subjective information.

In a separate paper, Cameron (2002), we describe models intended to capture the nature of the opinion-updating process as survey respondents are exposed to external information about the probable future state of the world's climate. The present paper focuses on an analysis of the same subjects' willingness to pay to prevent climate change. This willingness to pay is elicited using a referendum-type stated preference question (Arrow, et al. (1993)).

The objective of this analysis is modest. We wish to set forth a simple illustration that captures the most important features of any model intended to measure the social benefits of climate change mitigation: individual subjective uncertainty and estimation in terms of option prices formally derived from a common underlying indirect utility function that allows for 
heterogeneous preferences across individuals. The importance of incorporating these features is illustrated using a convenience sample, rather than a representative population sample, so further research is clearly warranted. We find that individual support for climate change mitigation programs depends not only on the anticipated scope of climate change, but also on the individual's degree of uncertainty about this scope. Furthermore, the effects of scope and uncertainty are not constant across individuals, but vary systematically with a number of sociodemographic and attitudinal characteristics.

How does this line of inquiry differ from the existing literature on climate change mitigation benefits? An early study that prompted much discussion in the literature was Mendelsohn, et al. (1994). These authors use county-level data on farmland prices for the US to develop a detailed climate and agriculture model. They control for non-climatic variables (including population density, latitude, altitude, and physical properties of the land in each county) and focus on the effects of interpolated county-level 30-year averages for normal daily mean temperature and normal monthly precipitation for January, April, July, and October. Their cropland models suggest annual damages on the order of $4-5 \%$ of gross farm income. Their crop revenue models, however, suggest about a $1 \%$ gain in revenue. However, scientifically forecasted climate changes and econometrically forecasted changes in agricultural revenues or cropland values are not necessarily an accurate or complete measure of the average citizen's perceptions of the climate problem and their willingness to support policies that will end up costing them money.

Work by Layton and Brown (2000) is much more relevant to the present study, although it still deals with only one type of climate change impact. These authors also use stated preference techniques, in this case to value a range of potential forest losses due to climate 
change. The program choices that were presented to respondents differed randomly in the level of forest loss that would ensue, whether forest management activities were involved, whether climate change abatement was included, and in the cost of the programs. Random parameters logit models were employed to ascertain that willingness to pay to prevent forest loss of different extents and over two different time horizons. Layton and Levine (2002) also employ the data from the Layton and Brown study but use a novel hierarchical Bayesian model to focus on the questions of scope effects (i.e. the idea that differing expectations about future climate conditions should produce a different willingness to pay to prevent climate change) and individual discount rates for climate change policy choices.

The present paper differs from Mendelsohn, et al. (1994), Layton and Brown (2000) and Layton and Levine (2002) in that demand for climate change mitigation is modeled as a derived demand for the control of future annual average temperatures in the respondent's region. We focus on the individual respondent's perceptions about this underlying climate variable, rather than on market or non-market demands for just some subset of climate services, such as agriculture or the maintenance of forest ecosystems. In addition, we emphasize the fact that, for many people, there is likely to be uncertainty about future climate conditions. In addition to verifying the existence of simple scope effects, we explore for the presence of uncertainty effects. When people's perceptions about climate change differ, both in terms of mean and variance, do these differences show up in their willingness to support climate change mitigation programs?

Section 2 reviews (in the general case) the modeling of option prices for environmental protection in the context of discrete-choice stated preference survey data. Uncertainty is captured by crude measures of the moments of respondents' subjective probability density 
functions for just one representative continuous dimension of future environmental quality: average annual temperatures in the respondent's region. Section 3 gives a concrete example in terms of a particular simple functional form for state-dependent individual indirect utility. Section 4 describes a convenience sample of college student data that allows the basic model to be tested, and Section 5 discusses the empirical results based on these data. Section 6 outlines some illustrative simulations that are possible using the estimated model, and Section 7 concludes.

\section{A Generic Model}

Suppose we are interested in determining an ex ante measure of the social value of preventing a deterioration in environmental quality. (In our application, environmental quality will refer to regional climate conditions.) Suppose initially that environmental quality can be conveniently summarized (in just one dimension) as the level of a continuous variable, $t$. For example, in the context of climate change, one could think of $t$ as annual average temperatures.

Assume that if mitigation is undertaken (at known cost), environmental quality at the current level, $t^{*}$, is guaranteed. If society fails to mitigate, the level of environmental quality is likely to worsen, but individuals are subjectively uncertain as to the extent of this deterioration. ${ }^{2}$ From the point of view of a single individual, let this uncertain future outcome--in the absence of intervention--be $t$. When called upon to make an evaluation about whether to undertake mitigation efforts, individuals decide whether or not to pay to prevent environmental degradation based on their current perceived distribution for $t$, which we will label $f(t)$. The way in which individuals formulate their own subjective distributions for $t$ (partly in response to information

\footnotetext{
${ }^{2}$ Arrow (1982) compares notions of risk perception in the disciplines of psychology and economics.
} 
from external sources) is one of the main issues in an associated paper (Cameron (2002)), but discussion of this topic will be minimized in the present paper.

\section{a.) General Discussion of Option Prices from Referendum Stated Preference Responses}

Under uncertainty, the appropriate measure of the social value of preventing environmental deterioration from $t^{*}$ to $t$ is the option price (OP) for this change. An option price in this context is that one common certain payment (an amount to be paid regardless of which way the uncertainty is resolved) that yields the same expected utility as the set of (differing) payments that would be separately optimal for each possible state of the world if it occurred with certainty. ${ }^{3}$ The economic theory concerning option prices is very familiar in the case of uncertainty over only two possible states of the world. (See for example, Graham (1981), or an empirical adaptation in an environmental economics context by Cameron and Englin (1997).) Identical intuition can be brought to bear on a problem with a continuum of possible states of the world, where uncertainty is represented by a continuous probability density function, rather than simply the discrete probabilities of an event and its complement. In order to estimate option prices empirically, it is expedient to work with a class of indirect utility functions that is additively separable in some monotonic function of income, $g(Y)$. Indirect utility is also affected by $h(t, x)$, a function of the realized level of environmental quality, $t$, and other individual-specific factors, $\mathrm{x}$. Ex ante, individual subjective uncertainty exists across states of the world (environmental quality outcomes), represented by different values of $t$. However, for any one state, the individual can be modeled as having state-

\footnotetext{
${ }^{3}$ Of course, economists have noted that expected utility theory is not adequate to explain every economic decision under uncertainty. It is, however, a conventional theoretical starting point that appears well suited to the present application. See Machina (1987) for a simple overview of some competing theories.
} 
dependent ${ }^{4}$ utility level $V^{1}$ if they elect to pay an offered amount, $c$, in order to preserve environmental quality at current level $t^{*}$. If they do not pay, environmental quality will deteriorate to the uncertain level $t$, distributed $f(t)$, which allows a utility level of only $V^{0}$. An additive normal error term facilitates econometric estimation.

$$
\begin{aligned}
V^{1}\left(Y-c, t^{*}\right) & =g(Y-c)+h^{1}\left(t^{*}, x\right)+\varepsilon^{1} \\
V^{0}(Y, t) & =g(Y)+h^{0}(t, x)+\varepsilon^{0}
\end{aligned}
$$

The individual will prefer to pay amount $c$, and thereby to preserve current environmental quality $t^{*}$, if $\left(V^{1}-V^{0}\right)$ is positive, i.e. if

$$
\left(V^{1}-V^{0}\right)=g(Y-c)-g(Y)+\left[h^{1}\left(t^{*}, x\right)-h^{0}(t, x)\right]+\left(\varepsilon^{1}-\varepsilon^{0}\right)>0 .
$$

If one particular value of $t$ was to occur with certainty, the individual's maximum willingness to pay (WTP) for preventing environmental deterioration from $t^{*}$ to specific level $t$ could be found by setting $\left(V^{1}-V^{0}\right)$ to zero and solving for $c_{t}^{*}$, which will of course differ with $t$. Simplify by letting $\varepsilon=\varepsilon^{0}-\varepsilon^{1}$ and solve for $c_{t}^{*}$ follows:

$$
\begin{aligned}
g\left(Y-c_{t}^{*}\right) & =g(Y)-\left[h^{1}\left(t^{*}, x\right)-h^{0}(t, x)\right]+\varepsilon \\
Y-c_{t}^{*} & =g^{-1}\left\{g(Y)-\left[h^{1}\left(t^{*}, x\right)-h^{0}(t, x)\right]+\varepsilon\right\} \\
c_{t}^{*} & =Y-g^{-1}\left\{g(Y)-\left[h^{1}\left(t^{*}, x\right)-h^{0}(t, x)\right]+\varepsilon\right\}
\end{aligned}
$$

An ex post measure of consumer welfare, across all possible states of the world $t$-- usually called the "expected surplus"--could then be calculated by computing the probability-weighted average of these state-dependent WTP values, namely, the expectation over $t$ :

\footnotetext{
${ }^{4}$ We use the term "state-dependent" in the same sense as it is used in Hirshleifer and Riley (1992). Preferences differ across the uncertain outcomes (states of the world), but only because the state of the world is an argument of a more-general specification of the individual's utility function.
} 


$$
\begin{aligned}
E_{t}\left[c_{t}^{*}\right] & =E_{t}\left[Y-g^{-1}\left\{g(Y)-\left[h^{1}\left(t^{*}, x\right)-h^{0}(t, x)\right]+\varepsilon\right\}\right] \\
& =\int\left[Y-g^{-1}\left\{g(Y)-\left[h^{1}\left(t^{*}, x\right)-h^{0}(t, x)\right]+\varepsilon\right\}\right] f(t) d t
\end{aligned}
$$

When explicit functional forms have been selected for $g, h^{1}$ and $h^{0}$, this integral can typically be simplified.

However, this ex post measure is not appropriate for ex ante policy decisions. The option price $(O P)$ is the preferred measure, and is defined by:

$$
\int V^{1}\left(Y-O P, t^{*}\right) f(t) d t=\int V^{0}(Y, t) f(t) d t
$$

or, identically,

$$
\int\left\{V^{1}\left(Y-O P, t^{*}\right)-V^{0}(Y, t)\right\} f(t) d t=0
$$

Substituting the generic expression for the indirect utility difference (from equation (2) into (6) ) yields:

$$
\int\left\{g(Y-O P)-g(Y)+\left[h^{1}\left(t^{*}, x\right)-h^{0}(t, x)\right]+\varepsilon\right\} f(t) d t=0
$$

Solving this equation for $O P$ yields the desired option price. One can simplify the notation by using $E_{t}[\cdot]$ to denote an expectation over states of the world $t$.

$$
\int g(Y-O P) f(t) d t=E_{t}[g(Y)]-E_{t}\left[h^{1}\left(t^{*}, x\right)-h^{0}(t, x)\right]+\varepsilon
$$

This analysis cannot be taken much further without committing to a specific functional form, especially for the function $g(Y)$. Thus, we proceed in the next section to adopt one simple concrete assumption for an empirically tractable functional form. 


\section{Example: A Specific Functional Form}

We require a simple functional form for the state-dependent indirect utility function that exhibits risk aversion and therefore allows ex ante option prices to differ from the ex post expected surplus measures. One such model is linear in the logarithm of income. Since $t$ differs across the mitigate/don't-mitigate stated preference scenarios concerning climate change, indirect utility can be linear in $t$. However, we also desire to allow the dispersion of the respondent's subjective distribution of future environmental quality to affect option prices. It is therefore expedient to allow indirect utility to depend upon the squared deviation between realized $t$ and its ex ante expected value, $E[t]$. A simple and tractable specific form for the model is therefore:

$$
\begin{aligned}
V^{1}\left(Y-c, t^{*}\right) & =\beta_{0} \log (Y-c)+\delta_{0} t^{*}+\delta_{1}\left(t^{*}-E\left[t^{*}\right]\right)^{2}+\varepsilon^{1} \\
V^{0}(Y, t) & =\beta_{0} \log (Y)+\delta_{0} t+\delta_{1}(t-E[t])^{2}+\varepsilon^{0}
\end{aligned}
$$

This symmetric loss function, for departures from $E[t]$, still leaves something to be desired, but it is a useful and tractable starting point. The utility-difference function, which also depends on the uncertain outcome with respect to $t$, is then:

$$
\left(V^{1}-V^{0}\right)=\beta_{0} \log [(Y-c) / Y]+\delta_{0}\left(t^{*}-t\right)+\delta_{1}\left\{\left(t^{*}-E\left[t^{*}\right]\right)^{2}-(t-E[t])^{2}\right\}+\left(\varepsilon^{1}-\varepsilon^{0}\right)
$$

In practice, each of the indirect utility parameters in this specification can be expressed as a systematic function of observable (exogenous) respondent attributes, in order to allow for heterogeneity in preferences. For example, we might let $\beta_{0}=\beta_{0}{ }^{\prime} x, \delta_{0}=\delta_{0}{ }^{\prime} x$ and $\delta_{1}=\delta_{1}{ }^{\prime} x$, where the vector $x$ may differ across these three systematic varying parameters. Also let $\varepsilon=\varepsilon^{1}-\varepsilon^{0}$. Note that if $t^{*}$ can be assumed to be certain, the term $\left(t^{*}-E\left(t^{*}\right)\right)^{2}$ is conveniently zero. 


\section{a.) Option Prices from Referendum Stated Preference Responses}

As in the generic case, OP is the common certain payment that has the same expected utility as no payment and no mitigation (or the same expected utility as the set of each of the separately optimal payments under each possible outcome with certainty). The binary probit discrete choice model (to be used to estimate OP) is based on the expectation of the utility difference across all possible outcomes for $t$. For the simple indirect utility difference specification illustrated above, this expectation takes the form:

$$
\begin{aligned}
E_{t^{0}}\left[V^{1}-V^{0}\right]= & \beta_{0} \log [(Y-c) / Y] \\
& +\int \delta_{0}\left(t^{*}-t\right) f(t) d t \\
& +\int \delta_{1}\left\{\left(t^{*}-E\left[t^{*}\right]\right)^{2}-(t-E[t])^{2}\right\} f(t) d t+\varepsilon
\end{aligned}
$$

If we assume that with mitigation, the current level of environmental quality can be sustained with certainty, this can be simplified as follows:

$$
\begin{aligned}
E_{t^{0}}\left[V^{1}-V^{0}\right]= & \beta_{0} \log [(Y-c) / Y]+\delta_{0}\left\{t^{*}-E[t]\right\} \\
& +\delta_{1} \int\left\{-(t-E[t])^{2}\right\} f(t) d t+\varepsilon
\end{aligned}
$$

Since the remaining expression involving an integral is simply the negative of the variance of $t^{0}$, the discrete choice probit "index" expression is thus a linear-in-parameters function of the indirect utility function parameters - the three scalars (or possibly systematically varying parameters consisting of the inner products of parameter vectors and exogenous variables) $\beta_{0}$, $\delta_{0}$, and $\delta_{1}:^{5}$

\footnotetext{
${ }^{5}$ Note that in the current empirical application, $t^{*}$ is invariant.
} 


$$
E_{t}\left[V^{1}-V^{0}\right]=\beta_{0} \log [(Y-c) / Y]+\delta_{0}\left\{t^{*}-E[t]\right\}+\delta_{1}\{-\operatorname{Var}[t]\}+\varepsilon
$$

For a sample of survey respondents, we can now provide an inventory of the data required in order to estimate the model. The dependent variable is the discrete YES/NO response to the willingness to pay for mitigation question. Explanatory variables must be constructed from data on income, $Y$, the referendum offered value, $c$, the certain level of environmental quality with mitigation $t^{*}$, and individual characteristics $x$, which can be allowed to shift each of the three basic utility parameters. The key explanatory variables capturing "scope" are constructed from the mean and the variance of the individual's subjective distribution concerning future environmental quality in the absence of mitigation: $E[t]$ and $\operatorname{Var}[t]$. Approximations for each of these variables are elicited from each respondent in our survey. One insight is that the precise shape of this subjective environmental quality distribution, $f(t)$, can apparently be individual-specific and take any valid form. Only the mean and the variance of this distribution affect the expected utility difference under this specification, which is a convenient artifact of this functional form.

The model, as specified above, is linear in parameters. If $E[t]$ and $\operatorname{Var}[t]$ are treated as ordinary explanatory variables, a conventional packaged maximum likelihood probit algorithm can be used to estimate the unknown parameters. Note that the intercept should be suppressed.

To solve the estimated probit discrete choice model for option prices in this concrete example, recall that $O P$ is the value of $c$ that makes the expected utility difference exactly zero. Substituting $O P$ for $c$ (and simplifying the notation to highlight the essentials), the $O P$ equation, for each individual, will take the following form:

$$
E_{t^{0}}\left[V^{1}-V^{0}\right]=\beta_{0} \log [(Y-O P) / Y]+A+\varepsilon,
$$


where $A=\delta_{0}\left\{t^{*}-E[t]\right\}+\delta_{1}\{-\operatorname{Var}[t]\}$. Setting the expected indirect utility-difference equal to zero and solving for $O P$ yields $O P=Y-Y \exp \left[-(A+\varepsilon) / \beta_{0}\right]$. Note that the error term ought to be carried throughout this process. Calculating a fitted value for an individual's $O P$ involves taking the expectation of this formula over the implicit probit error term $\varepsilon$ (which is assumed, as usual, to be distributed normally with mean zero and variance one). The expectation of $O P$ for each individual is given by:

$$
E\{O P\}=Y-Y \exp \left(-A / \beta_{0}\right) \exp \left(1 /\left(2 \beta_{0}^{2}\right)\right)
$$

In the discussion of the empirical results later in this paper, we will also refer to the quantity $E\{O P\}$ as willingness to pay $(W T P)$.

\section{A Modest Sample of Data}

After two rounds of pretests, a pencil-and-paper questionnaire was distributed to Summer Session undergraduate economics classes. Students received a five minute introduction to the survey during the lecture period and were requested to return the completed survey by the next lecture. ${ }^{6}$ A second round of sampling was conducted in two classes in the Fall quarter of that same year, and a third round of sampling, using similar classes, took place during the subsequent Fall quarter. Table 1 gives descriptive statistics for the estimating sample.

${ }^{6}$ The Summer Session 1977 samples employed no incentives and yielded a rather low response rate, as expected. The Fall 1997 (SMPL2) and Fall 1998 (SMPL3) samples were collected in the author's own Principles of Economics classes and Applied Regression Analysis classes. In these courses, the survey was integrated into the instruction in segments concerning the non-market valuation of public goods and the application of nonlinear simultaneous equations and probit models. Nominal extra credit was attached to submitting an anonymous survey and a detached "receipt" with the student's name and section number. This protocol was designed to preserve anonymity yet reward participation. The number of surveys collected was only slightly smaller than the number of receipts turned in, and only a handful of submitted survey instruments were turned in blank. Given the exploratory nature of the sample, we obviously did not (and could not) pursue non-respondents. 
This is undeniably a "sample of convenience" so it would be heroic to attempt to extrapolate the findings from this sample concerning mean option prices to the population as a whole. Nevertheless, this sample can be used to demonstrate that there can be systematic differences across individuals in perceptions about future climate conditions and that these different perceptions can influence willingness to pay for climate change mitigation. Any given group of college students can be different from the population as a whole, but the extent to which they differ may depend upon the type of college, the students' majors, or the courses they are taking when surveyed. The most important differences are likely to be age- or cohortrelated. ${ }^{7,8}$

An anonymous referee has summed up some of the issues: "college students are the age group closest to adult status that are also most likely to be living at the time we see effects of these policies. Thus, under this view they are the ones that should be answering these questions. A key caveat is that if the votes are taken by all today and cost experienced today, we must reflect others' views as well."

\section{a. Data on Respondents' Opinions about Future Environmental Conditions}

A preliminary task in this study involves establishing the determinants of the moments of

\footnotetext{
${ }^{7}$ Harrison and Lesley (1996), however, find that an inexpensive student sample yields essentially identical results to those provided by litigation-quality research in the Exxon Valdez case.

8 Using data from another study (Cameron, et al. (2002)), we have created a dummy variable for the youngest 19 - to 25 -year age group (2.3\% of the 1737 people in the sample), and separately for the 19 - to 29 -year age group (6.7\% of the sample). These dummy variables were allowed to shift both the intercept and the slope of the implicit willingness-to-pay function, for the "best" model in that study. For the 19-25 group, the intercept term was statistically significantly different but only at the $10 \%$ level. The slope term was not statistically different. When the 19-29 group is distinguished from the rest, the intercept term is not statistically different, but the slope term is significantly different, although only just at the $10 \%$ level. Perhaps due to the small numbers of "youths" in these two different subsamples, these tests are inconclusive as to whether WTP for environmental non-market goods differs significantly from that of adults.
} 
the individual's revised subjective distribution for future environmental quality (average annual temperatures): $E[t]$ and $\operatorname{Var}[t]$. There has been substantial policy interest in recent years in the topic of risk communication (e.g. Davies, et al. (1987)). This literature focuses on the best way to convey to individuals the true objective magnitudes of risks. ${ }^{9}$ There has been less attention devoted to the problem of eliciting subjective probabilities. Reliable elicitation of (at least) the means and variances of subjective probability distributions is crucial to this analysis. ${ }^{10}$

In economics, the topics of (i.) individuals' risk perceptions, (ii.) how these risk perceptions respond to information, and (iii.) the value of risk changes, have been fertile areas for research. Some representative studies include Smith and Desvousges (1987), Smith and Desvousges (1988), Smith and Johnson (1988), Viscusi (1985), Viscusi (1985), Viscusi and Magat (1992), Viscusi, et al. (1986), and Viscusi and O'Connor (1984). In almost all cases, however, the risks under consideration are physical health or workplace risks. But "risk" can be defined more broadly to include preferences over uncertain outcomes more generally.

For climate change, the variable that we designate to illustrate the uncertainty is annual average temperature during a decade twenty years into the future. At the beginning of the survey, we elicit from the respondent their initial assumptions about the future distribution of the $t$ variable. Historical data are provided for the weather station nearest the respondent. Provision of this information insures that the respondent is making his or her forecast for the expected value and dispersion of future mean temperatures (for the decade of 2011-2020) based on valid current data.

After establishing the true local annual average temperature, we first elicit information on

\footnotetext{
${ }^{9}$ The issue of long-term environmental risks is addressed in Fischhoff (1990).

${ }^{10}$ Benson, et al. (1995) address the role of belief assessment in the process of eliciting probabilities.
} 
the mean and dispersion of the individual's native subjective distribution for future

environmental quality. Expected values seem relatively easy to elicit. It is more difficult to ask respondents to convey information on variances. For dispersion measures, we have elected to ask for "plus" and "minus" amounts relative to their expected value (and described as a 95\% range), and then to interpret this as four standard deviations, squaring 0.25 times this amount to yield a variance approximation.

Once these prior distributions have been established, the respondent is presented with information describing the distributions of future average temperatures (purportedly) forecasted by government scientists and by environmental groups. ${ }^{11}$ One objective of the larger study was to discriminate among the effects of different external information sources on the respondent's distributional updating process. The design of the different survey versions ensures that there is orthogonal variation across respondents in these purported external forecasts.

After the external information on future climate has been provided, respondents are invited to update their priors on the distribution of future annual average temperatures, giving both a new expected value and a new 95\% range (which we convert to a variance, again invoking strong distributional assumptions). In the present paper, these updated posterior distributions constitute the information set used by respondents at the moment they make their stated choice about climate change policy. A thorough analysis of the updating process from native priors to posterior distributions is contained in Cameron (2002). To the extent that there is heterogeneity in this updating process, changes in population characteristics can be expected

\footnotetext{
${ }^{11}$ This information is part of the experimental design of the survey. All stylized forecasts fall within the range of assorted actual forecasts. Concerning survey research ethics, there is the delicate matter of not lying to respondents. Since we are purposefully vague about the precisely which "government scientists" and "environmental groups" have made these forecasts, there may be some natural attenuation of the credibility assigned by respondents to these opinions. Respondents were debriefed after the sample period.
} 
to alter the way external information is combined with priors to generate the posterior information used in policy choices. In the present paper, however, we take these posterior distributions as given and explore their effects on stated climate policy choices.

\section{b.) Data on Willingness to Pay to Prevent Climate Change}

No established markets exist for the mitigation of climate change. Furthermore, there are few opportunities to invoke weak complementarity and to rely on indirect market information to infer implicit demands for climate change mitigation. Despite the potential shortcomings of stated preference methods, direct elicitation of people's stated willingness to trade off money for environmental protection is likely to be the best source of information about the social value of climate change mitigation activity.

Prior to the policy choice question from which we attempt to infer valuation, the survey respondent has been asked their opinion about climate change prospects in terms of average annual temperatures in their regions. However, we also invite respondents to consider the implications for a variety of climate services of an arbitrary four-degree (Fahrenheit) average temperature increase. Demand for climate services give rise to derived demand for climate change mitigation. These effects on climate services are captured by questions concerning heating costs, air-conditioning costs, personal comfort, food prices, severity of storms, frequency of storms, frequency of droughts, water consumption [prices], housing prices, sea levels, tropical diseases, welfare of the poorest $50 \%$ of US residents, and welfare of the poorest $50 \%$ of the world's population. Having explored with the respondent the anticipated consequences of failing to prevent a standardized temperature increase, we then review the respondent's probable budget constraint over the relevant future period. We elicit expected annual income categories (in 1997 
dollars) for the year 2005 and the year 2020. The proposed policy is described as follows:

Suppose that policy-makers have identified a set of domestic and international environmental regulations and incentives. If put into place, these policies will prevent any detectible change in your regional climate so that average temperatures will continue, indefinitely, to be much as they were during 1987-1996. In other words, putting these policies in place would allow society to avoid any of the consequences (bad or good) to be expected if we do nothing.

The monthly costs of the policy are assigned randomly, in ten different amounts, presented in the following form:

Suppose that these policies will mean higher prices and/or higher taxes so that by the year 2000, your monthly household costs will be higher by $\$$ (in 1997 dollars) for as long as these policies are followed.

The offered amounts were uniformly distributed across the values $\$ 5, \$ 10, \$ 15, \$ 20, \$ 30, \$ 50$, $\$ 75, \$ 100, \$ 125$, and $\$ 150$ in the first installments of the survey. Initial analyses showed a disproportionate number of respondents saying yes, even to the highest amounts. For the final wave of the survey, the $\$ 5, \$ 15$ and $\$ 30$ bids were discontinued and were replaced by bids of $\$ 35, \$ 200$, and $\$ 300 .^{12}$

Respondents are then asked if they would vote in favor of this package of policies, given their expected income and these costs. They are then probed to detect "protest bids." The last part of the survey collects sociodemographic and attitudinal variables, including the respondent's perceptions of bias (for or against the policy) on the part of the research team.

The basic option price model can be estimated using data on: the YES/NO response to this question, the exogenously assigned value of monthly costs, $c$, imposed for this respondent,

\footnotetext{
${ }^{12}$ A handful of left-over survey instruments from the earlier wave were recycled during the final wave of the survey. Of these, the returns at the discontinued bids of $\$ 5, \$ 15$ and $\$ 30$ were 5, 1 , and 2 questionnaires, respectively.
} 
information on other sociodemographic characteristics, $s$, current environmental quality $t^{*}$ (current average annual temperature, equal to 63.5 degrees Fahrenheit for everyone in this geographically homogeneous sample), and the values of $E[t]$ and $\operatorname{Var}[t]$. Table 1 provides variable definitions and descriptive statistics.

\section{Empirical Findings}

How willing are respondents to vote in favor of the climate change mitigation policies at different levels of cost? Given the microeconomic theory behind our estimating specification, and with sufficient confidence in stated preference information, the discrete choice probit model explaining stated voting behavior can be used to infer fitted estimates of individuals' option prices for climate change mitigation. Table 2 displays the results from some preliminary models in terms of expected values (E) and variances (V) using our exploratory sample. These models are labeled as "EV" specifications. Note that $E\left[t^{*}\right]=t^{*}=63.5$ for all respondents in this sample. $^{13}$

Our most basic estimating specification is derived theoretically from a utility difference function with three parameters (the coefficients $\beta_{0}, \delta_{0}$ and $-\delta_{1}$ on $\log [(Y-c) / Y], E[t]$, and $\operatorname{Var}[t]$ respectively). Introducing respondent heterogeneity (potentially) generalizes each of these three parameters to a linear function of individual attributes. This is how we accommodate preferences that differ according to the observable characteristics of different groups of respondents.

\footnotetext{
13 We have employed $E\left[t^{*}\right]-63.5$ in our models, rather than $63.5-E\left[t^{*}\right]$. This will have no substantive effect whatsoever in the formal linear or ad hoc quadratic models (only sign changes in some coefficients), but it facilitates later consideration of ad hoc logarithmic specifications.
} 
Model EV-1 is the most rudimentary specification, since it assumes homogeneous preferences. The initial term, $\log [(Y-c) / Y]$, ought always to be important, since it captures both the effect of income and that of policy costs. It is solidly significant in all the specifications shown in Table 2. In Model EV-1, however, while the coefficient on $E[t]$ is statistically significant, the coefficient on the uncertainty term, $\operatorname{Var}[t]$, is near zero and completely insignificant. Furthermore, no amount of experimentation with sociodemographic shifters on the coefficients of this model seems able to produce a robust specification wherein a linear term in uncertainty is solidly statistically significant.

Our theoretical model motivated the inclusion of an uncertainty term in our model, and the simple indirect utility function we chose for illustration leads to a linear empirical specification. For welfare calculations, however, we do not need to recover the underlying utility function from the utility-difference specification. It seems reasonable, then, to explore generalizations of our basic theoretical model that may prove to be more compatible with the empirical data.

Linear-in-variables specifications can sometimes obscure strong non-linear relationships. Model EV-2 in Table 2 shows the results of including squared terms in $E[t]$ and $\operatorname{Var}[t]$, as well as an interaction between the two (still with constant parameters). The effect is dramatic. In particular, the squared and interaction terms in variance are statistically significant at the $10 \%$ and $5 \%$ levels, suggesting that uncertainty is indeed a determinant of support for climate change mitigation policies. The three new parameters produce a substantial and significant improvement in the maximized log-likelihood. Thus, the relationship between WTP and $E[t]$ and $\operatorname{Var}[t]$ is not planar. In fact, this model leads us to believe that it is a "saddle"-shaped 
surface. However, the common sense of the model must be assessed.

First of all, the saddle shape of the surface persists when we generalize Model EV-2 by allowing the parameters to vary with individual heterogeneity as in Model EV-3. The coefficient on $\log [(\mathrm{Y}-\mathrm{t}) / \mathrm{Y}]$ may vary with gender, and the coefficient on $E[t]$ varies with the respondent's subjective degree of informedness. (We preserve the interaction term between the $E[t]$ variable and the conservatism variable because of its marginal significance in other specifications.) None of the other slope coefficients in Model EV-2 prove to be robustly heterogeneous across the sample. Model EV-3 in Table 2 is our most general fully quadratic specification.

Model EV-3 suggests that WTP increases with the anticipated severity of climate change $(E[t])$ when uncertainty is low, but as uncertainty increases - into a region where the data are rather thin ${ }^{14}$ - the effect of $E[t]$ on WTP changes sign. This seems implausible, unless having a high value for $E[t]$ is correlated with some key omitted variable(s) that also influence(s) demand for climate change mitigation efforts.

There are also very few data points to support some extremely high fitted WTP implied by the fully quadratic model for scenarios that display little expected change in temperature but are high on the uncertainty dimension. It is conceivable that in order for the quadratic form to adequately fit the curvature in the surface over the mass of the data, the coefficients on the squared and interaction terms produce these high $W T P$ values over the sparsely populated domain merely as an artifact of achieving the best fit over the densely populated domain. It seems we need to explore models that allow for curvature, but do not, for example, force a change in sign for $\partial W T P / \partial E[t]$ as uncertainty about future average temperatures increases. 
We now depart further from our initial simple theoretical model by switching from a dependence of WTP upon $\operatorname{Var}[t]$ to a family of models wherein WTP depends on the precision of the individual's average future temperature forecast, $1 / \operatorname{Var}[t]$. This model is likely to be somewhat ill-behaved, however. As the case of certainty is approached (i.e. as $\operatorname{Var}[t]$ goes to zero), this precision variable becomes undefined. Consequently, we adopt an arbitrary minimally shifted model, employing $1 /(\operatorname{Var}[t]+1)$ in order to capture the dispersion in future temperature forecasts without creating undefined $W T P$ as uncertainty approaches zero. Attempts at models that were fully quadratic in $E[t]$ and this precision variable revealed that the only persistently significant terms were $1 /(\operatorname{Var}[t]+1)$ and $E[t]$. This specification is shown in Table 2 as Model EV-4.

Qualitatively, Model EV-4 produces a fitted WTP surface where WTP is increasing in $E[t]$ at low levels of $E[t]$, but decreasing in $E[t]$ at higher levels. This still seems questionable, so we consider models where the deviation between current and expected future temperatures enter in $\log$ form. ${ }^{15}$

The best-fitting model in this class is Model EV-5. Its log-likelihood value is -331.95 , only minimally worse than Model EV-4's value of -330.94 . This slight loss in fit is the cost of preventing outliers from leading us to a model with implausible properties. Squared terms in the $\log (E[t]-60)$ variable and in the $1 /(\operatorname{Var}[t]+1)$ prove to be statistically insignificant, and have

\footnotetext{
${ }^{14}$ The bulk of the data reside between 63.5 and 70 degrees for $E[t]$ and less than 9 for $\operatorname{Var}[t]$.

${ }^{15}$ A minor adjustment is made because five respondents report negative value for $E[t]-63.5$, i.e., they expect

average temperature to be lower in the future. Rather than discarding these observations, we use $\log (E[t]-60)$ instead, to ensure that we need not attempt to take the log of a negative number.
} 
thus been dropped.

The robustness of Model EV-5 to outlying observations has been verified by dropping 26 observations that appear to qualify as outliers in the domain of the $E[t]$ and $\operatorname{Var}[t]$ variables. In Figure 1, these observations have values of $E[t]$ greater than 71, values of $\operatorname{Var}[t]$ greater than 12 or values of $\operatorname{Var}[t]$ greater than 8 when $E[t]$ is less than 66 . When these observations are dropped, Model EV-5's point estimates are only minimally affected. The coefficient on the interaction term slips just below the $10 \%$ significance level, but the other parameters retain significance at their previous levels. Although the baseline effects of $\log (E[t]-60)$ and $1 /(\operatorname{Var}[t]+1)$ become statistically insignificant in Model EV-5, the interaction terms involving these variables remain significant, so they are retained in the model. ${ }^{16}$

An anonymous reviewer drew our attention to the theme in Cook and Graham (1977), Anderson (1979), Graham (1981) and Graham (1984) that the central element in determining the shape of the option price function is how the marginal utility of income changes with the events at risk. This reviewer recommended that that we verify our assumed independence of the marginal utility of log income from the distribution of future annual average temperatures. We generalized Model EV-5 to include interactions between $\log [(Y-c) / Y]$ and each of the mean and variance terms-- $\log (E[t]-60)$ and $1 /(\operatorname{Var}[t]+1)$. Neither of these interaction terms bears a coefficient that is individually significant and the maximized value of the log-likelihood improves by only 0.91 for these two additional sources of systematic variation in the marginal

\footnotetext{
16 The introduction of larger possible costs (\$200 and \$300) in the second wave of the survey instrument could have the potential to increase implied willingness-to-pay values since these higher values present respondents with an opportunity to say "yes" to a larger bid. Nevertheless, there is no statistically significant shift in willingness to
} 
utility of log income. It appears that the fit of the model is not greatly compromised by assuming separability between income and climate effects.

Model EV-5 will be considered our preferred specification in this class of models. The implications of this model are clearest if we use a three-dimensional plot. Figure 1 shows the resulting surface. The vertical dimension measures fitted monthly WTP in constant 1997 dollars. We have benchmarked this surface for an income level of $\$ 40,000$ (approximately the average household income in 1998), despite the fact that these students optimistically expect their future incomes to be over $\$ 60,000$ in constant 1997 dollar terms, on average. The $W T P$ surface is furthermore depicted for males with neutral levels on the scales for informedness and conservatism. $^{17}$ The vertical scale ranges from $\$ 0$ to $\$ 500$. Clearly, there are scope effects in willingness to pay to prevent climate change. The greater the amount of climate change that respondents expect they are preventing, the more they are willing to pay. With certainty that temperatures will remain just as they have been (at 63.5 degrees Fahrenheit), WTP for climate change mitigation programs is very small. The more certain the respondent is about a given increase in average temperatures, the more he or she is willing to pay per month to prevent such an increase. Uncertainty appears to dampen the effect of the scope of expected climate change on willingness to pay to prevent it, but even with substantial uncertainty, scope effects appear to remain. Given that attempts to include squared terms in $\log (E[t]-60)$ and $1 /(\operatorname{Var}[t]+1)$ in Model 5 did not improve the log-likelihood, it appears that WTP is monotonic in both $E[t]$ and $\operatorname{Var}[t]$ over the range of our data.

pay is evidenced for different waves of the survey in the family of models presented in Table 2.

17 For the reported average expected future income in this sample, the $W T P$ value would simply be scaled upwards by about $50 \%$, for an expected annual income of just over $\$ 60,000$. 
Why is WTP decreasing, rather than increasing with uncertainty? In the usual story about the risk premia associated with gambles, we are considering uncertainty concerning the level of a good (typically income). Total utility is assumed to be increasing with income, but at a decreasing rate, so that the marginal utility of income is positive, but declining. The result is that a positive risk premium must be added to a gamble (in terms of income) to make the individual indifferent between a gamble and a sure payment with the same expected value as the gamble. In contrast, in the climate change context, the uncertainty concerns future annual average temperatures. Higher temperatures appear to be perceived, on average, as bads, rather than goods. Total utility is declining in future annual average temperatures. Marginal utility is negative and seems to be declining with increases in future annual average temperatures. When marginal utility is negative, uncertainty is associated with a negative risk premium. Hence, the greater the uncertainty about future climate, the less people are willing to pay to sustain current climate patterns.

Construct validity is an important factor in any assessment of a fitted model of WTP. We consider the sensitivity of the shape of the WTP surface to gender, informedness about environmental issues, and the respondent's degree of conservatism, respectively. Female students are willing to pay more than males, greater informedness means greater willingness to pay, and greater conservatism means lower willingness to pay. These findings are intuitively plausible.

Note that three additional variables were considered in the most extensive forms of all specifications discussed in this paper: RES. BIAS (researcher bias), and SMPL2 and SMPL3 (dummy variables for two of the main subsamples of data). None of these three variables appears to have a statistically significant effect on $W T P$ in any specification. 


\section{Simulations}

The estimated coefficients on the FEMALE, INFORM, and CONSERV variables convey the differences in the fitted WTP function for individuals with different characteristics. We have also conducted a few simple simulation exercises to demonstrate the implications of our model for how WTP in our sample would differ under a number of counterfactual conditions concerning individuals' expectations and uncertainty about future climate conditions in the absence of mitigation programs.

Simulations are necessary because the point estimates of option price are non-linear functions of the data and the estimated model parameters. Equation (15), or its analogs for different specifications, can be used to produce point estimates of WTP (the expected value of $O P$ ) for each individual in the sample. One can report fitted $W T P$ at the means of the data. An alternative is to report descriptive statistics for these fitted point estimates (the median and lower and upper quartiles) calculated across all individuals in the sample. We provide both in Table 3.

For these simulations, we employ the indirect utility-difference probit equation of Model EV-5 in Table 2. The first two lines in the body of Table 3 display descriptive statistics for fitted expected option prices (with expected future monthly income statistics for comparison). Option price point estimates ( $W T P$ ) range widely in the sample, with all of this variation attributable to differences in expected income and other individual attributes. ${ }^{18}$ While a point estimate of $\$ 228$ per month may seem high, it remains less than $5 \%$ of average expected future monthly income.

Note that confidence intervals for these WTP estimates are not provided. The nonrepresentative sample could lead to a false sense of certainty about our predictions for WTP in

\footnotetext{
18 As individual expected option prices are calculated, rare estimates less than zero are counted as zero.
} 
the population as a whole. With a more representative sample of data, it would be advisable to explore other specifications. The asymptotically normal distributions of the maximum likelihood parameter estimates cause trouble when one tries to divide through by $\beta_{0}$ in calculating the option price, OP. The mean of a ratio of normally distributed variables is undefined. While a mean WTP will be observed in any finite sample, the expected value is technically undefined.

If people retained their subjective uncertainty about future average temperatures (i.e. if $\operatorname{Var}[t]$ remained unchanged), but everyone's expected temperature increase was just one degree Celsius, WTP at the data means would drop from $\$ 228$ to $\$ 171$. If they expected a 2 degree Celsius increase, WTP would increase to $\$ 262$.

Eliminating everyone's uncertainty about future climate (i.e. setting $\operatorname{Var}[t]=0$ for everyone, but leaving their individual $E[t]$ unchanged) would increase $W T P$ from $\$ 228$ to \$490. Eliminating all uncertainty and convincing everyone that there would be a temperature increase of exactly one degree Celsius would increase $W T P$ from $\$ 228$ only to $\$ 363$. However, a certain temperature increase of two degrees Celsius would boost WTP to $\$ 526$ at the means of the data otherwise. The magnitudes of these WTP numbers may of course have been influenced by the proximity of the sample period to the local hot-weather season.

\section{Conclusions and Directions for Future Research}

Due to the small convenience sample used for the empirical portion of this study, the findings from the analysis of this survey are not conclusive. They are, however, suggestive. The derivation of a simple but rigorous model of the theoretic underpinnings of a referendum discrete 
choice model for climate change mitigation is an important beginning. Option prices have been argued to be the correct theoretical construct for cost-benefit analysis of public policies under uncertainty. A simple model with state-dependent preferences with a well-defined indirect utility function is shown in this paper to lead to a convenient starting point for empirical specifications for use with respondent's subjective assessments of the expected value and variance of future climate conditions.

This degree of rigor allows the estimated model to be solved for the theoretically appropriate valuation construct. However, using this formal model as a starting point for the empirical example quickly reveals that a model which is simply linear in the expected value and variance of the individual's subjective distribution of future average annual temperatures is dominated by richer models that allow for non-constant slopes with respect to mean and variance in the main "index" of the model. We have examined several alternative empirical specifications that do a better job of fitting the data, but these do not sustain an easy, clean mapping back to the underlying indirect utility function. Fortunately, the willingness to pay measures that are relevant to welfare analysis do not really require knowledge of the underlying indirect utility function.

Wherever the estimated parameters of our option price models are statistically significant, their signs are plausible. Knowledge of the nature of heterogeneity in preferences with respect to climate change mitigation will be a very important consideration in the politics of "selling" (or derailing) climate change mitigation policies. We have found persuasive evidence that, even in this small sample, the anticipated scope of climate change in the absence of mitigation makes a statistically significant difference in individuals' willingness to pay for mitigation. Greater climate uncertainty also seems to reduce people's willingness to incur the 
costs of climate change mitigation-moreso when larger temperature increases are expected.

Further resolving the role of uncertainty about future climate in determining the strength of support for climate change policies should be an important item on the research agenda. The results in this paper certainly suggest that, for any group that is trying to limit support for climate change mitigation, a campaign to amplify uncertainty about future climate conditions will lead to reduced support for mitigation policies. ${ }^{19}$ This is consistent with the persistent efforts of some of the stakeholders who will bear many of the costs of climate change mitigation to "debunk" climate change science by emphasizing how little scientists "really know."

19 This is reminiscent of the idea of "optimal obfuscation" put forward by Magee, et al. (1989) to explain why vote-maximizing strategies with endogenous politics can lead to economically inefficient solutions. 


\section{ACKNOWLEDGEMENTS}

As this paper has evolved, it has benefited from comments received at presentations at the CERE/NOAA Conference on Research Transformations in Environmental Economics: Policy Design in Response to Global Change at Duke University (May 5-6, 1997) and at the EML/NSF Symposium on Preference Elicitation at UC Berkeley (July, 1997), the World Congress of Environmental and Resource Economists, Venice, Italy (June, 1998), and the Canadian Resource and Environmental Economics meeting, Guelph, Ontario, Canada (October, 2000). Kathleen McGarry, Fred Luk, Michael Sproul, Ed McDevitt, and Pari Kasliwal were immensely helpful in the data collection phase. Thanks are due to Vic Adamowicz, Anna Alberini, Ryan Bosworth, Graham Crawford, JR DeShazo, Barri Grossman, Jack Hirshleifer, Kathleen McGarry, V. Kerry Smith and two anonymous reviewers for helpful comments, to Sara Wong Chang for careful data entry, and to Casey Williams for assistance in assembling the survey instruments. Any remaining errors are my own. 


\section{REFERENCES}

Anderson, J.E., 1979. Measurement of welfare cost under uncertainty. Southern Economic Journal 45 (4), 1160-1171.

Arrow, K., 1982. Risk perception in psychology and economics. Economic Inquiry 20, 1-9.

Arrow, K.J., Solow, R., Leamer, E.E., Portney, P., Radner, R., 1993. Report of the NOAA panel on contingent valuation. Federal Register 58, 4601-4614.

Benson, P.G., Curley, S.P., Smith, G.F., 1995. Belief assessment - an underdeveloped phase of probability elicitation. Management Science 41 (10), 1639-1653.

Cameron, T., Poe, G., Ethier, R., Schulze, W., 2002. Alternative nonmarket value-elicitation methods: Are the underlying preferences the same? Journal of Environmental Economics and Management 44 (3), 391-425.

Cameron, T.A., 2002. Updating subjective risks in the presence of conflicting information: An application to climate change. Department of Economics, University of Oregon. Eugene, OR.

Cameron, T.A., Englin, J., 1997. Respondent experience and contingent valuation of environmental goods. Journal of Environmental Economics and Management 33 (3), 296-313.

Cameron, T.A., Englin, J., 1997. Welfare effects of changes in environmental quality under individual uncertainty. Rand Journal of Economics 28 (0), S45-S70.

Cook, P.J., Graham, D.A., 1977. Demand for insurance and protection - case of irreplaceable commodities. Quarterly Journal of Economics 91 (1), 143-156.

Davies, J.C., Covello, V.T., Allen, F.W. (Eds.) 1987. Risk communication. Proceedings of the national conference on risk communication, Conservation Foundation, Washington, DC. 
Fischhoff, B., 1990. Understanding long-term environmental risks. Journal of Risk and Uncertainty 3, 315-330.

Graham, D.A., 1981. Cost-benefit-analysis under uncertainty. American Economic Review 71 (4), 715-725.

Graham, D.A., 1984. Cost-benefit-analysis under uncertainty - reply. American Economic Review 74 (5), 1100-1102.

Harrison, G.W., Lesley, J.C., 1996. Must contingent valuation surveys cost so much? Journal of Environmental Economics and Management 31 (1), 79-95.

Hirshleifer, J., Riley, J.G., 1992. The analytics of uncertainty and information. Cambridge University Press, New York, NY.

Layton, D.F., Brown, G., 2000. Heterogeneous preferences regarding global climate change. Review of Economics and Statistics 82 (4), 616-624.

Layton, D.F., Levine, R.A., 2002. How much does the far future matter? A hierarchical Bayesian analysis of the public's willingness to mitigate ecological impacts of climate change. Daniel J. Evans School of Public Affairs, University of Washington. Seattle, WA. 29.

Machina, M., 1987. Choice under uncertainty: Problems solved and unsolved. Journal of Economic Perspectives 1, 121-154.

Magee, S.P., Brock, W.A., Young, L., 1989. Black hole tariffs and endogenous policy theory: Political economy in general equilibrium. Cambridge University Press, New York.

Mendelsohn, R., Nordhaus, W.D., Shaw, D., 1994. The impact of global warming on agriculture - a ricardian analysis. American Economic Review 84 (4), 753-771.

Smith, V.K., Desvousges, W., 1987. An empirical analysis of the economic value of risk changes. Journal of Political Economy 95, 89-114. 
Smith, V.K., Desvousges, W., 1988. Risk perception, learning and individual behavior. American Journal of Agricultural Economics 70, 1113-1117.

Smith, V.K., Johnson, F.R., 1988. How do risk perceptions respond to information? The case of radon. Review of Economics and Statistics 70 (1), 1-8.

Tversky, A., Kahneman, D., 1974. Judgment under uncertainty: Heuristics and biases. Science $185,1124-1131$.

Viscusi, W.K., 1985. A Bayesian perspective on biases in risk perception. Economics Letters 17, $59-62$.

Viscusi, W.K., Magat, W.A., 1992. Bayesian decisions with ambiguous belief aversion. Journal of Risk and Uncertainty 5, 371-387.

Viscusi, W.K., Magat, W.A., Huber, J., 1986. Informational regulation of consumer health risks an empirical-evaluation of hazard warnings. Rand Journal of Economics 17 (3), 351-365.

Viscusi, W.K., O'Connor, C., J., 1984. Adaptive responses to chemical labeling: Are workers Bayesian decision decision makers. American Economic Review 74 (5), 942-956. 
Table 1

Descriptive Statistics for Complete Estimating Sample $(\mathrm{n}=602)$

\begin{tabular}{llll}
\hline VARIABLE DESCRIPTION & MEAN & STD. DEV \\
\hline
\end{tabular}

Distributions of future annual mean temperature: (degrees Fahrenheit)

$\begin{array}{rlcc}E[t] & \text { Subjective expected future annual mean temperature. } & 66.73 & 1.871 \\ \operatorname{Var}[t] & \text { Subjective variance in future annual mean temperatures } & 2.237 & 2.307 \\ H[t]^{\mathrm{a}} & \text { Subjective "high guess" for future annual mean temperature } & 69.60 & 2.593 \\ L[t]^{\mathrm{a}} & \text { Subjective "low guess" for future annual mean temperature } & 64.15 & 1.708\end{array}$

Incomes, Cost, and Vote:
Y Expected income in 2005
c Monthly cost of policies
$\begin{array}{rr}61267 . & 30585 . \\ 79.45 & 70.08\end{array}$
WTP? Vote for policies? $(1=\mathrm{yes}, 0=$ no)
0.79

Respondent Attributes:

AGE Age of respondent (17- to 23-year-old sample) 19.39

FEMALE Gender $(1=$ female, $0=$ male $)$

0.4967

INFORM consider myself well-informed about environmental
Issues" $(1$ =strongly disagree , 7 =strongly agree $)$

CONSERV

"I consider myself to be..."

IMMOBILE

$(1=$ extremely liberal, $7=$ extremely conservative $)$

Same region as I do now."

$(1=$ strongly disagree, $7=$ strongly agree $)$

$\begin{array}{llll}\text { RES. BIAS } \quad \text { “...I suspect that the [team] conducting this study believes } & 5.267 & 1.129\end{array}$ that preventing climate change is ( 1 = extremely unnecessary, 7 =extremely urgent $)$

SMPL2 Membership in Fall 1997 subsample 0.3920

SMPL3 Membership in Fall 1998 subsample $\quad 0.4950$

\footnotetext{
${ }^{\text {a }}$ Variable is used explicitly in an Appendix, available from the author.
} 
Table 2

Constant Parameter and Systematic Varying Parameter Specifications

for the Indirect Utility-Difference Function based on Expectation and Variance (EV):

$(\mathrm{n}=602 ; \mathrm{n}(1)=436, \mathrm{n}(0)=166$; asymptotic $\mathrm{t}$-test statistics in parentheses $)$

\begin{tabular}{|c|c|c|c|c|c|}
\hline \multirow{2}{*}{$\begin{array}{l}\text { Transformation: } \\
\text { Variable }\end{array}$} & \multicolumn{4}{|c|}{$f(x)=x-63.5$} & \multirow{2}{*}{$\frac{f(x)=\log (x-60)}{E V-5^{a}}$} \\
\hline & EV-1 & $\mathrm{EV}-2$ & EV-3 & EV-4 & \\
\hline $\log [(\mathrm{Y}-\mathrm{c}) / \mathrm{Y}]$ & $\begin{array}{l}4.683 \\
(2.06)^{* *}\end{array}$ & $\begin{array}{l}9.113 \\
(3.77)^{* *}\end{array}$ & $\begin{array}{l}12.90 \\
(4.08)^{* *}\end{array}$ & $\begin{array}{l}13.83 \\
(4.32)^{* *}\end{array}$ & $\begin{array}{l}14.40 \\
(4.44)^{* *}\end{array}$ \\
\hline $\begin{array}{r}\log [(\mathrm{Y}-\mathrm{c}) / \mathrm{Y}] \\
\times \text { FEMALE }\end{array}$ & - & - & $\begin{array}{l}-6.056 \\
(-1.60)\end{array}$ & $\begin{array}{c}-6.638 \\
(-1.76)^{*}\end{array}$ & $\begin{array}{c}-6.730 \\
(-1.79)^{*}\end{array}$ \\
\hline $\mathrm{f}(\mathrm{E}[\mathrm{t}])$ & $\begin{array}{c}0.1774 \\
(7.00)^{* *}\end{array}$ & $\begin{array}{c}0.3928 \\
(7.39)^{* *}\end{array}$ & $\begin{array}{c}0.2454 \\
(2.74)^{* *}\end{array}$ & $\begin{array}{l}0.1446 \\
(1.63)\end{array}$ & $\begin{array}{l}0.2115^{\mathrm{a}} \\
(1.28)\end{array}$ \\
\hline $\begin{array}{r}f(E[t]) \\
\times \text { INFORM }\end{array}$ & - & - & $\begin{array}{c}0.05374 \\
(3.98)^{* *}\end{array}$ & $\begin{array}{r}0.05090 \\
(3.85)^{* *}\end{array}$ & $\begin{array}{l}0.08301^{\mathrm{a}} \\
(3.38)^{* *}\end{array}$ \\
\hline $\begin{array}{r}\mathrm{f}(\mathrm{E}[\mathrm{t}]) \\
\times \text { CONSERV }\end{array}$ & - & - & $\begin{array}{l}-0.01793 \\
(-1.29)\end{array}$ & $\begin{array}{l}-0.01758 \\
(-1.29)\end{array}$ & $\begin{array}{l}-0.04925^{\mathrm{a}} \\
(-1.90)^{*}\end{array}$ \\
\hline $\operatorname{Var}[\mathrm{t}]$ & $\begin{array}{l}-0.004791 \\
(-0.18)\end{array}$ & $\begin{array}{l}-0.01606 \\
(-0.27)\end{array}$ & $\begin{array}{l}-0.01460 \\
(0.24)\end{array}$ & - & - \\
\hline$f(E[t])^{2}$ & - & $\begin{array}{l}-0.02459 \\
(-3.30)^{* *}\end{array}$ & $\begin{array}{c}-0.02034 \\
(-2.63)^{* *}\end{array}$ & $\begin{array}{c}-0.02090 \\
(-3.08)^{* *}\end{array}$ & - \\
\hline $\operatorname{Var}[\mathrm{t}]^{2}$ & - & $\begin{array}{c}0.01254 \\
(1.87)^{* *}\end{array}$ & $\begin{array}{c}0.01470 \\
(2.09)^{* *}\end{array}$ & - & - \\
\hline $\mathrm{f}(\mathrm{E}[\mathrm{t}]) \times \operatorname{Var}[\mathrm{t}]$ & - & $\begin{array}{l}-0.02728 \\
(-2.26)^{* *}\end{array}$ & $\begin{array}{l}-0.03387 \\
(-2.67)^{* *}\end{array}$ & - & - \\
\hline $1 /(\operatorname{Var}[\mathrm{t}]+1)$ & - & - & - & $\begin{array}{c}0.5079 \\
(2.25)^{* *}\end{array}$ & $\begin{array}{l}-1.454 \\
(-1.51)\end{array}$ \\
\hline $\mathrm{f}(\mathrm{E}[\mathrm{t}]) /(\operatorname{Var}[\mathrm{t}]+1)$ & - & - & - & - & $\begin{array}{r}1.033^{\mathrm{a}} \\
(1.73)^{*}\end{array}$ \\
\hline Max Log L & -356.97 & -338.93 & -328.98 & -330.94 & -331.95 \\
\hline
\end{tabular}

${ }^{a}$ In Model 5, $(\mathrm{E}[\mathrm{t}]-63.5)$ is replaced by $(\mathrm{E}[\mathrm{t}]-63.5-3.5)=(\mathrm{E}[\mathrm{t}]-60)$. This avoids the problem of taking the $\log$ of a negative number for the five observations where expected future average temperature is less than current average temperature. 
Table 3

Counterfactual Simulations for WTP

Descriptive Statistics Across Sample for Fitted Individual Option Prices

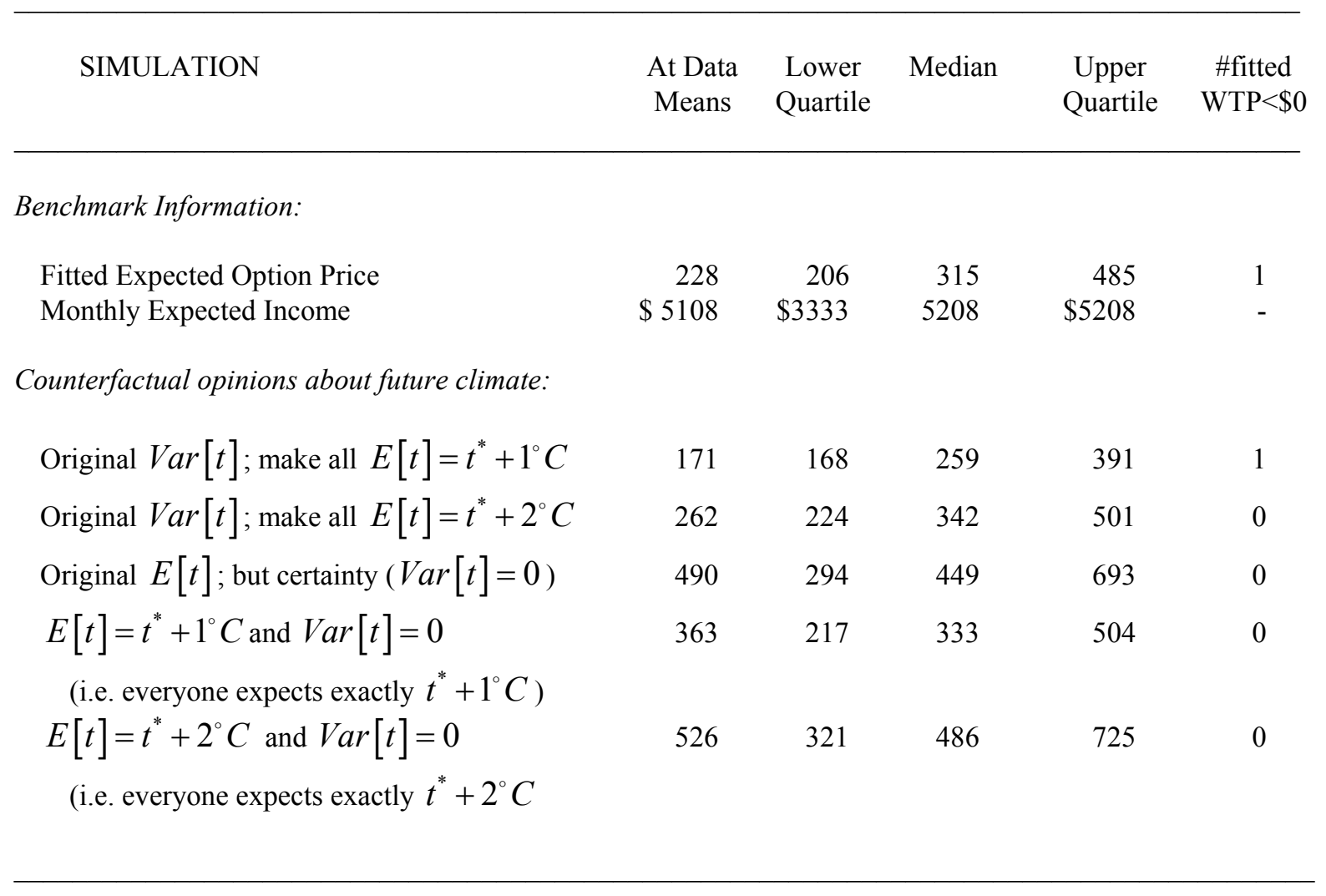

NOTE: $t^{*}$ is current annual average temperature. Variation in fitted option prices across the sample is due to heterogeneity in the explanatory variables. Number of observations with negative fitted WTP is reported because functional form does not restrict monthly expected Option Price to be non-negative. 
Figure 1

WTP surface according to Model EV-5

(Male; Income $=\$ 40,000$, Informedness and Conservatism=neutral)
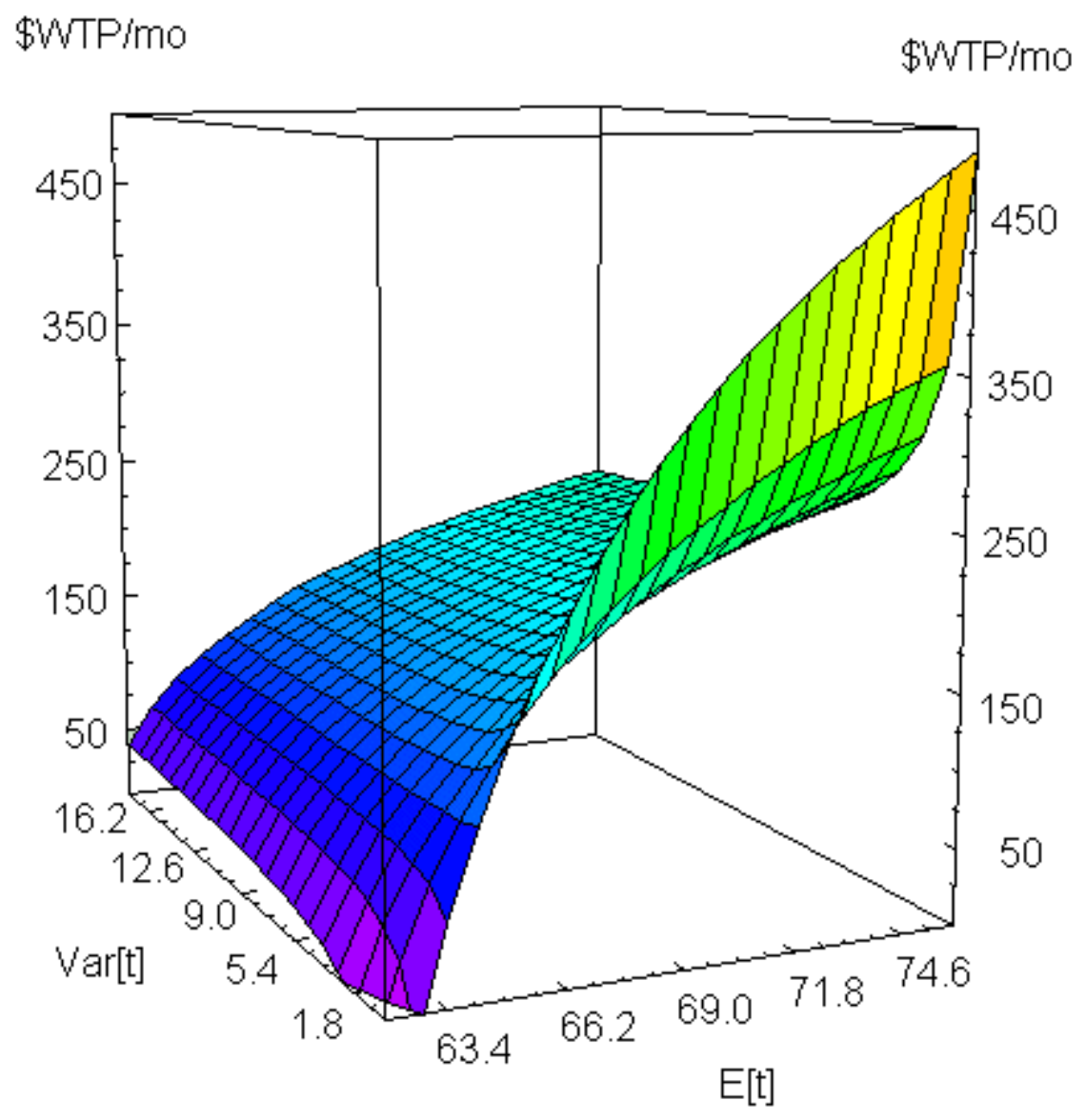


\section{APPENDIX I}

The sizes and frequencies of the randomly assigned "bids" in the stated preference experiment may be of interest to some readers.

Table A1

WTP by Bid Size

$$
(\mathrm{n}=602, \mathrm{n}(0)=166, \mathrm{n}(1)=436)
$$

\begin{tabular}{rcc}
\hline Bid & \%Yes WTP & $\begin{array}{c}\text { number } \\
\text { at bid }\end{array}$ \\
\hline 5 & 87.50 & $32^{*}$ \\
10 & 84.75 & 59 \\
15 & 75.00 & $28^{*}$ \\
20 & 81.36 & 59 \\
30 & 73.68 & $38^{*}$ \\
35 & 79.31 & $29^{* *}$ \\
50 & 72.58 & 62 \\
75 & 67.80 & 59 \\
100 & 70.18 & 57 \\
125 & 67.24 & 58 \\
150 & 62.32 & 69 \\
200 & 51.61 & $31^{* *}$ \\
300 & 71.43 & $21^{* *}$ \\
\hline & & \\
\hline
\end{tabular}

* bids were discontinued for the F98 instrument

** bids were introduced for the F98 instrument 


\section{Appendix II}

\section{Alternative Specifications}

A referee has suggested that since my specification departs from the prescriptions of my theoretical model beyond the first column of Table 2 , it is reasonable to consider other atheoretic specifications as well. This referee proposed considering models that use not an inferred variance measure, but the more primitive information on dispersion that is actually collected by the survey, which can be called $H[t]$ and $L[t]$, the respondent's "high guess" and "low guess" concerning likely future average temperatures in his or her region. Table A2 presents results from four such models, which are labeled "EHL" for "expected value," "high guess," and "low guess.” Models EHL-1 and EHL-2 are linear models which assume homogeneous and heterogeneous preferences and use simply the divergences between $E[t], H[t]$ and $L[t]$ and the 63.5 degree Fahrenheit current annual average temperature. $H[t]$ appears to be the only significant scope variable in the homogeneous case. Allowing for heterogeneous preferences reveals that scope effects differ with informedness, degree of conservatism, and the likelihood that the individual will reside in the same region in the future. However, given the nonlinearities that appear to be present in the EV models discussed in the body of this paper, we also consider logarithmic specifications. Models EHL-3 and EHL-4 use a log transformation of each temperature measure (relative to a benchmark set at 58.5 degrees Fahrenheit to avoid negative arguments in the logarithms). While none of the individual scope effects is significant in the model with homogeneous preferences, model EHL-4 reveals the heterogeneity that one might, by now, expect. In this richer model, the index of the probit model now varies in a statistically significant fashion with $E[t]$ and $H[t]$. Since the maximized value of the log-likelihood 
attained with these two (non-nested) transformation is higher in the logarithmic case, Model EHL-4 is preferred in this class.

Model EHL-4 preserves only the most significant of the interaction terms that have been examined. The WTP surface that is implied by model EHL-2 is depicted in Figure A1 for males with neutral levels of informedness and conservatism, and a midrange probability of remaining in the same region in the future. The figure requires some explanation. There are now three arguments, $E[t], H[t]$ and $L[t]$, so it is not possible to depict $W T P$ as a function of all three simultaneously. Instead, we display the WTP surface that the model would predict if $L[t]$ implicitly departs from $H[t]$ symmetrically below $E[t]$. The surface is shown only over the domain where $H[t]>E[t]$. The key features of the relationship continue to hold. With certainty (i.e. along the diagonal in Figure A1), WTP increases at a decreasing rate with $E[t]$. Off the diagonal, as increasing uncertainty causes $H[t]$ (and $L[t]$ ) to depart symmetrically more and more from $E[t]$,WTP declines.

These models are somewhat less satisfactory than those in the body of the paper because of the need to shift the variables by 58.5 degrees, rather than 63.5 , in order to prevent the need to take a logarithm of a negative number, for those respondents who believe that one of the three statistics, $E[t], H[t]$ and $L[t]$, will be less than 63.5 degrees in the future. 


\section{Table A2}

Models using Raw Data on Expected, High Guess and Low Guess (EHL) for Annual Average Temperature $(\mathrm{n}=602 ; \mathrm{n}(1)=436, \mathrm{n}(0)=166)$

\begin{tabular}{|c|c|c|c|c|}
\hline \multirow{2}{*}{$\begin{array}{c}\text { Transformation: } \\
\text { Variable }^{\mathrm{a}}\end{array}$} & \multicolumn{2}{|c|}{$f(x)=x-63.5$} & \multicolumn{2}{|c|}{$f(x)=\log (x-58.5)$} \\
\hline & EHL-1 & EHL-2 & EHL-3 & EHL-4 \\
\hline $\log [(\mathrm{Y}-\mathrm{c}) / \mathrm{Y}]$ & $\begin{array}{c}6.601 \\
(2.79)^{* *}\end{array}$ & $\begin{array}{l}11.08 \\
(3.52)^{* *}\end{array}$ & $\begin{array}{l}10.27 \\
(4.15)^{* *}\end{array}$ & $\begin{array}{l}14.98 \\
(4.59)^{* *}\end{array}$ \\
\hline $\begin{array}{r}\log [(\mathrm{Y}-\mathrm{c}) / \mathrm{Y}] \\
\times \text { FEMALE }\end{array}$ & - & $\begin{array}{c}-6.542 \\
(-1.70)^{*}\end{array}$ & - & $\begin{array}{c}-6.973 \\
(-1.84)^{*}\end{array}$ \\
\hline $\mathrm{f}(\mathrm{E}[\mathrm{t}])$ & $\begin{array}{l}-0.001848 \\
(-0.03)\end{array}$ & $\begin{array}{l}-0.2129 \\
(-0.92)\end{array}$ & $\begin{array}{l}0.2181 \\
(0.37)\end{array}$ & $\begin{array}{l}-0.2685 \\
(-0.14)\end{array}$ \\
\hline $\mathrm{f}(\mathrm{E}[\mathrm{t}]) \times \mathrm{INFORM}$ & - & $\begin{array}{c}0.1202 \\
(2.61)^{* *}\end{array}$ & - & $\begin{array}{c}0.7681 \\
(2.14)^{* *}\end{array}$ \\
\hline$f(E[t]) \times I M M O B I L E$ & - & $\begin{array}{l}-0.06116 \\
(-1.83)^{*}\end{array}$ & - & $\begin{array}{c}-0.5844 \\
(-2.09)^{* *}\end{array}$ \\
\hline $\mathrm{f}(\mathrm{H}[\mathrm{t}])$ & $\begin{array}{c}0.1062 \\
(2.86)^{* *}\end{array}$ & $\begin{array}{l}0.1756 \\
(1.33)\end{array}$ & $\begin{array}{l}0.01818 \\
(0.04)\end{array}$ & $\begin{array}{l}0.4753 \\
(0.29)\end{array}$ \\
\hline $\mathrm{f}(\mathrm{H}[\mathrm{t}]) \times \mathrm{INFORM}$ & - & $\begin{array}{l}-0.03862 \\
(-1.53)\end{array}$ & - & $\begin{array}{c}-0.6094 \\
(-1.94)^{*}\end{array}$ \\
\hline $\mathrm{f}(\mathrm{H}[\mathrm{t}]) \times \mathrm{CONSERV}$ & - & $\begin{array}{l}-0.01613 \\
(2.10)^{* *}\end{array}$ & - & $\begin{array}{c}-0.05016 \\
(-2.47)^{* *}\end{array}$ \\
\hline $\mathrm{f}(\mathrm{H}[\mathrm{t}]) \times \mathrm{IMMOBILE}$ & - & $\begin{array}{l}0.03468 \\
(1.87)^{*}\end{array}$ & - & $\begin{array}{c}0.5045 \\
(2.07)^{* *}\end{array}$ \\
\hline $\mathrm{f}(\mathrm{L}[\mathrm{t}])$ & $\begin{array}{l}0.03180 \\
(0.65)\end{array}$ & $\begin{array}{l}0.03608 \\
(0.70)\end{array}$ & $\begin{array}{l}0.1896 \\
(0.85)\end{array}$ & $\begin{array}{l}0.1284 \\
(0.56)\end{array}$ \\
\hline Max $\log L$ & -352.14 & -338.59 & -343.43 & -329.63 \\
\hline
\end{tabular}

${ }^{\text {a }}$ Each temperature measure is expressed as a deviation from 58.5 degrees Fahrenheit, rather than from the current annual average temperature of 63.5 degrees Fahrenheit. This arbitrary displacement ensures that no negative values are created for any of the three temperature measures when a few individuals anticipate any one of these temperatures (typically the "low guess" to be lower than current average. 
Figure A1

WTP Surface According to Model EHL-4

(if $\mathrm{H}[\mathrm{t}]$ and $\mathrm{L}[\mathrm{t}]$ are symmetric around $\mathrm{E}[\mathrm{t}]$; displayed only for domain where $\mathrm{H}[\mathrm{t}]>\mathrm{E}[\mathrm{t}]$ )

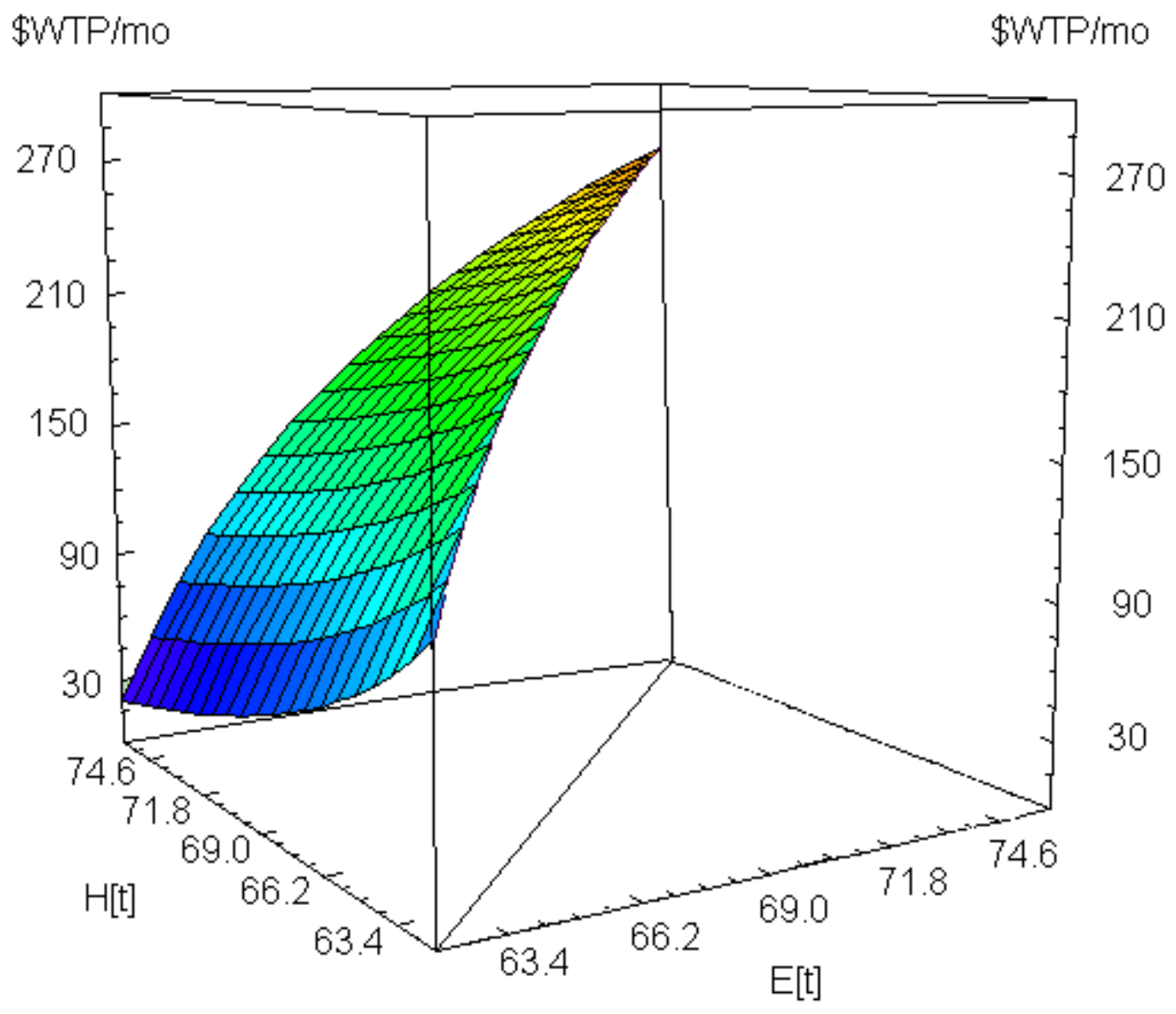

